\title{
Employees' Perceptions Of The Current Incidence And Causes Of Tobephobia In Their Working Environment
}

\author{
Prakash Singh, Nelson Mandela Metropolitan University, South Africa
}

\begin{abstract}
In any organization, there are definite signs of the fear of failure, which impacts negatively on the organization's culture and consequently inhibits the employees' outputs. Managing human resources becomes a challenge in any organization because of the employees' achievement gap between job expectations and job outcomes. Motivational research on achievement situations avers that while some individuals have an achievement orientation, others can be imbued with a fear of failure orientation in their working environment. Studies over the past seven decades indicate that the fear of failure is a multifaceted form of avoidance motivation that can be linked to an acute emotional sensitivity when individuals fail to meet expectations. This failure-avoidant motive could result from a fear of change within one's environment. When this fear is associated with educational deficits within the environment, then the result is that individuals would experience the effects of tobephobia (TBP). In this study, TBP is defined as the fear of failure experienced by employees, such as teachers in their schools because of them lacking the professional competencies to achieve planned educational outcomes.
\end{abstract}

A multi-respondent survey design was used in this quantitative study, which focused on teachers' perceptions of the current incidence and causes of TBP in their working environment. The findings of this study confirm that TBP is not a myth, but a harsh reality affecting teaching and learning outcomes. As the findings of this exploratory study also strongly suggest, employers must not be complacent and evasive by ignoring problems that fester within their organizations.

Keywords: Tobephobia; Failure-Avoidant Motive; Employees’ Emotional Sensitivity; Job Training Deficits

\section{INTRODUCTION}

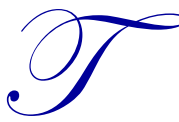

obephobia (TBP) is associated indelibly with the fear of failure pertaining to education (Singh, 2011; Singh, 2013a). Fear of failure can be defined as a disposition to "avoid failure in achievement settings because one feels shame on failure" (Elliot \& Thrash, 2004, p. 958). The question that arises is whether TBP is solely a constant of school-related experiences. Not so. The omnipresence of failure is aptly described by Filochowski (2013) when he states, "Failure isn't rare; it isn't that unusual. It's everywhere, in all corners of the working world" (p. 11). TBP can be experienced in any organization, be it the public or private sector (Filochowski, 2013; Greenberg \& Baron, 2000). Why? When employees in any organization, for instance, experience job training deficits in accomplishing their designated tasks which they are accountable for, then they would be definitely exposed to TBP (Singh, 2013a; Atkinson, 1957; Atkinson, 1964). Birney, Burdick, and Teevan's (1969) theory on the fear of failure strongly indicates that individuals attempt to escape from achievement-oriented situations because of their fear of failure in those situations. Motivational research on achievement situations avers that while some individuals have an achievement orientation, others can be imbued with a fear of failure orientation (Martin \& Marsh, 2003; Gastorf \& Teevan, 1980; McClelland, Atkinson, Clark, \& Lowell, 1953; Birney, Burdick, $\&$ Teevan, 1969; Singh, 2011; Singh, 2013a). Studies over the past seven decades indicate that fear of failure is a multifaceted form of avoidance motivation that can be linked to an acute emotional sensitivity when individuals fail to meet expectations (Atkinson, 1957; McGregor \& Elliot, 2005; Wright, Pincus, Conroy, \& Elliot, 2009; Singh, 
2013a). This failure-avoidant motive could result from a fear of change within one's environment (Gastorf \& Teevan, 1980). Ornstein and Hunkins (2004) succinctly capture the nature of change as follows:

People want to change; yet they are also afraid of change, especially if it comes quickly or if they feel they have little control or influence over it. People become accustomed to the status quo and prefer to make modifications in new behaviour in small and gradual steps. Most people, when they talk about change, and say they welcome it, often would prefer that other people within the organization change. (p. 301)

The effects of TBP are not only limited to the school as an organisation, but they can permeate the private and public sectors where educational qualifications are a prerequisite to hire employees in positions where they are required to demonstrate that they have the knowledge and skills to do the job (Singh, 2013a). Traditional organizational cultures fail to embrace an atmosphere of creativity and such - "stale behaviours and out-moded thinking dictate that the status quo is a safer bet" (Leach, 2013, p. 196). Employees are then unwilling to compromise their position and, unfortunately, such organizational barriers leave employees unfulfilled and frustrated at not being able to accomplish their goals. Maxwell (2001) notes that the frustration, hurt, or disappointment that we sense when our goals are not met is a feeling common to all of us and "perhaps it's the feelings about failure that cause many to begin to fear failure" (p. 98). Upgrading the employees' knowledge and skills to keep abreast of changes in the working conditions is a major challenge to employers. In measuring success and failure, Filochowski (2013) avers that:

When people define success as a clearly understood end point and then go on to describe the qualities of excellence or perfection which will ensure that it is achieved, they are making a fundamental error. Success cannot be pinned down to one thing. Excellence in one context may be mediocrity in another and downright under-performance in a third. Perfection in achieving one goal may mean completely missing the target on another one or even on a variant of the original goal. (p. 13)

The incidence and causes of TBP will therefore differ from one organization to another because each working environment has its own culture associated with its mission and vision. Filochowski (2013) found that every organization with significant tasks, from time to time faces difficulties and problems that it cannot resolve immediately. Because this forms part and parcel of its daily business, it does not therefore necessarily mean that the organization is failing. As pointed out by Leach (2013), fear is an emotion individuals create in their minds and it often results from a lack of confidence in their ability to handle situations or anxiety about the outcomes. The emotional turmoil created by their fear of failure can stunt their personal growth and impose limits on their beliefs, which would ultimately lead to a lacklustre performance in them achieving personal and organizational goals. As suggested by Leach (2013), embedding a performance culture is of equal importance to employees' daily work and life. In addressing one's fear of failure, McKay (2000) avers that:

The healthier strategy for controlling the fear of failure is to redefine the meaning of your mistakes. People with low self-esteem consider mistakes to be an indication of a general lack of worth. Each error reaffirms their underlying belief that something is terribly wrong with them. (p. 40)

Giroux (2003) draws attention to the changes that are frequently occurring in educational institutions such as schools. Giroux states that there is corporatisation of schools that is currently taking place which has implications on the workloads of teachers and the conditions in which they have to work. The adoption of corporate models of management, which are based on technocratic principles, tends to impact negatively on the morale of teachers (Carter, 2007). Corporate culture, managerialism, policies of control and surveillance, increasing workloads related to curriculum transformation, and declining benefits are factors that contribute to anxiety, stress, and the demoralization of teachers when systemic changes are made in education. Teaching is an intricate and challenging occupation and research confirms that, in recent years, it has become one of the highest stress professions (Engelbrecht, Oswald, Swart, \& Eloff, 2003; SAHRC, 2006; Rothstein-Fisch \& Trumball, 2008). Kyriacou (1998) defines teacher stress as "the experience by a teacher of unpleasant emotions, such as tension, frustration, anxiety, anger, and depression, resulting from his or her work as a teacher" (p. 4). Anxiety focuses the individual's attention on future loss (Gardner \& Bell, 2005; Chong, 2005). A phobia such as TBP tends to interrupt joyful and productive life experiences and functioning levels. It does not allow individuals to live in the present and it detaches them from 
their sense of reality (Gardner \& Bell, 2005). TBP means that individuals are displaying symptoms of anxiety, tension, and stress and could be suffering from mild to severe bouts of depression because of the fear that is engendered within their working environment (Martin \& Marsh, 2003; Menuey, 2005; Singh, 2006; Ginsberg \& Cooper, 2008). In this article, the focus is on the educators' perceptions of the current incidence and causes of TBP, which can range from their inability to usher in constant curriculum changes, as a result of their professional incompetencies, to their safety concerns in their working environment.

\section{CURRENT INCIDENCE AND CAUSES OF TOBEPHOBIA}

In any organization, there are definite signs of the fear of failure, which impacts negatively on the organization's culture and consequently inhibits the employees' outputs. According to Clarkson (2004), stress, pressure, and fear at work can cause tension, poor focus, fatigue, and distress. Absenteeism increases as weakened immune systems become more susceptible to illness. Six factors in organizations that evoke the incidence and causes of TBP are (Filochowski, 2013):

1. Ignorance: If an organization is ignorant of what is intrinsically important, nothing is prioritised. The sheer number of demands on employees leads to despair and inaction, or frantic attempts being made to satisfy each demand by running a little way in one direction, and then turning. A good example of this in schools is the imposition of administrative tasks to the already burdened teachers' workload, as well as assigning teachers' subjects to teach in which they had no training at all. Giving employees work that they are not trained to do is a recipe for disaster in terms of organizational outputs. Such activity is fruitless and baseless and destroys the morale of the employees when they cannot do what they have been primarily employed for. It usually occurs when employees feel overwhelmed with too many things coming at them at too fast a pace; e.g., curriculum change in schools without developing the curriculum competencies of teachers and managing discipline without a clear policy on school violence and drug abuse.

2. Certainty: In this situation, managers have an untested self-belief that they know all the answers and therefore don't need to consult anyone to seek the truth. If their conviction about being right is strong enough, such managers lacking collegiality will immunise themselves against alternatives and, in many cases, unwelcome explanations of what is going on and attack those who challenge them as disloyal. Such tobephobic managers would add to the incidence and causes of TBP in organizations such as schools.

3. Complacency: A major question of organizational effectiveness is whether its vision is still valid. Much change could have taken place without the vision being revamped to mirror its future goals and objectives. When managers and their employees still use outdated methods to deal with new challenges, the result is that problems remain stubbornly unresolved, typically with symptoms of organizational overload. Developing new skills of employees motivates them to be innovative rather than being complacent and fearful of change.

4. Obsession: If an organization, or its leadership, obsessively pursues a single goal at the expense of others, then this could be costly in terms of neglecting what appears to remain important. Such an obsession was clearly evident in many parts of the world, including South Africa, when outcomes-based education (OBE) was implemented in the absence of developing the teachers' professional skills to manage the new curriculum. The experiment with OBE met with such failure in South Africa that it has now been replaced with a standards-based curriculum embedded in the Curriculum and Assessment Policy Statements (CAPS). Having a vision for transformation does not make it automatically become a reality if the vision like OBE includes a number of variables that are not within the control of the organization.

5. Manipulation: This is about inaccurate reporting or it could be turning a blind eye. The introduction of OBE in South Africa was based on falsehood because teachers were experiencing fear of failure, but the educational authorities simply manipulated the educational system to enforce the implementation of a curriculum without having created the infrastructure to support it. The manifestation of TBP is a reality in many organizations such as failing schools, but few are brave and honest enough to admit its existence. Lines of job behaviours are there to ensure probity, honesty, and accuracy and it's important not to compromise them. In an unhealthy organizational culture, questions, such as "What are we doing wrong?" and "How could we do better?", are not usually asked because the assumption made is that everything is progressing smoothly despite this not being so. 
6. Evasion: Evasion can occur when individuals in a system collude to ignore a problem they are too frightened to acknowledge or tackle. An example of this is introducing curriculum change in schools without upgrading the knowledge and skills of teachers to implement the new curriculum. External factors will be blamed and it will lead employees to continue in their traditional approaches, fearing the consequences of addressing the problem at hand. In healthy organizational cultures, honesty is valued highly and would drive employees to question and assess their performance, to admit problems, and consequently open up pathways to deal with them. A prerequisite would therefore be to ensure that employees have the prerequisite skills to accomplish their designated tasks.

The incidence and causes of TBP can be linked to a number of achievement gaps in education, and this issue is evoked succinctly by Scherer (2010) as follows:

From the nefarious achievement gaps to the racial isolation in our increasingly segregated schools; from the digital divide that results in kids not having access to computers, to the poverty gulf that results in kids not having homes; from boys' reading difficulties and girls' problems with math, to the disparities among rural, suburban, and urban school needs - these gaps present baffling problems. (p. 7)

It is therefore becoming increasingly evident that schools function against a background of social ills which is exacerbated by a widening gulf between the rich and poor throughout the world. With the current economic recession being experienced globally, there is now an exponential increase in the risk factors associated with poverty and poor health, such as HIV/AIDS, affecting the provision of quality education. Every school, as an organization, is faced with challenges. Rooney (2010) brings up this issue clearly when she comments as follows:

Major crises confront schools everywhere. Lack of funding, pressure from high-stakes testing, unemployed parents, changing demographics, and increased class sizes are just a few of the factors that turn the normally difficult job of teaching into a challenge of gigantic proportions. (p. 87)

Usually, teachers' salaries are given as a reason for the high dropout rate of teachers. However, numerous studies (Singh, 2006; Singh, 2008; Singh, 2013a) confirm that a multitude of factors contribute to teachers suffering from burnout and thus exiting the profession. Burnout symptoms of TBP, such as anxiety, stress, bitterness, and pessimism, go undetected within the educational environment (Singh, 2011; Singh, 2013a). Even a lack of collegial support demotivates teachers and creates a sense of hopelessness amongst them (Singh, Manser, \& Dali, 2013; Singh, 2013b). Recent reports (Cassidy, 2006; SAHRC, 2006) indicate that young teachers are being driven out of the profession by violent pupils and a climate of fear in staffrooms, which stops experienced staff members from admitting that there are problems in the school. It is not uncommon to see teachers leaving the profession because of psychological violence and physical assault by learners. Benoit, Lecocq, and Phillipot (2007) identified verbal victimization by learners of teachers in their research as a major factor that impacted negatively on the emotional well-being of teachers. Inevitably, these factors demotivated and demoralized teachers in the execution of their duties. The violence experienced by teachers creates fear within the educational environment. As pointed out by Benoit et al., the fear manifesting in the educational environment is resulting in an exodus of teachers.

Several recent studies on the existence of TBP (Singh, 2008; Jali, 2010; Singh, 2011; Singh, 2013a; Lunn, 2009; Dawnward, 2010) allude to the following contributory factors of TBP in the educational environment:

- $\quad$ Lack of quality leadership in education

- Inadequate resources to cope with systemic changes in education

- $\quad$ Limited in-service training of teachers to cope with major curriculum changes which take place on a continuous basis

- $\quad$ Handling multilingualism and multiculturalism without the relevant skills

- $\quad$ Lack of collegiality within the educational environment to nurture the self-esteem of educators

- $\quad$ Fear of their (educators') safety, as well as the safety of learners because of threats from gangs

- $\quad$ Drug abuse amongst students

- $\quad$ Being unable to keep pace with technological innovations in education

- $\quad$ Poverty in the community

Copyright by author(s); CC-BY 
Lack of manageable workloads, the expansion of the curriculum, and a lack of continuous skill development have been cited by Conley and Glasman (2008) as sources of fear experienced by teachers. When widely publicised questions emerge about the relevance of the curriculum and the ability of teachers to teach it, then the uncertainty and the fear of failure would be inevitable outcomes. However, as pointed out by Harford (2011), when employees are faced with a mistake or a loss in knowing what to do, the right response would be to acknowledge the setback and change direction.

\section{EMPIRICAL STUDY}

A multi-respondent survey design was used in this empirical study. In such a design, the focus is on relationships between and among variables in a single group (Gravetter \& Wallnau, 2008; Tuckman, 1999). The subjects chosen to participate in the study were selected following a process described by McMillan and Schumacher (2001) as non-probability convenience sampling because the subjects were selected on the basis of their accessibility and availability. There was also an element of stratified sampling used (McMillan \& Schumacher, 2001). The final sample was neither random nor probability-based; it was a mixture of convenience and stratified sampling which ensured that the population represented a cross-section of teachers at all post levels. Hence, for the purpose of this study, the participants were teachers studying at the Nelson Mandela Metropolitan University (NMMU) in Port Elizabeth, South Africa. Ethics clearance to proceed with the study was granted by the university (NMMU).

The questionnaires were completed by teachers from Port Elizabeth and Durban (in South Africa) and although the subjects were used to generate comparative results, it was also important to ensure that the sample was not biased (see Table 1). Seeing that the main NMMU campus is based in Port Elizabeth, 78.8\% of the respondents were from this site. For ethical reasons, respondents were advised not to disclose their names and the names of their schools on the questionnaire. Confidentiality and anonymity were thus ensured and the participation of the respondents was on a totally voluntary basis. Of the 335 questionnaires distributed, 311 were returned, which represented a return rate of $92.8 \%$.

The structured questionnaire was initially compiled by the author of this paper. An extensive literature review on achievement motivation and the fear of failure experienced by teachers was consulted in the first stage of developing the questionnaire. This first draft copy was then subjected to further review and modification by a qualified statistician at NMMU. Thereafter, the second draft copy of the questionnaire was critically reviewed by four teachers, two principals, an academic with curriculum specialization, and an educational psychologist. In this preliminary phase of developing the questionnaire, the input of these specialists was considered to be adequate for this exploratory study. Their critical input was duly considered in finalizing the questionnaire. Qualitative means were thus used to ensure validity of the items. This process ensured the face and content validity of the measuring instrument used for this research. Further testing of the items in the questionnaire will be undertaken in additional studies. Use will be made of item response theory models of analysis to establish the construct validity of the questionnaire quantitatively.

The questionnaire was divided into two sections:

- $\quad$ Section A: The demographic variables of the participants

- $\quad$ Section B: A Tobephobia inventory

However, in terms of the delimitation and focus of this article, the following sub-sections of the questionnaire were used:

Sub-Section 2: Incidence of TBP experienced by teachers

Sub-Section 3: Causes of Tobephobia in the school environment

In Sub-Section 2 (see Table 2), respondents were required to respond to six items with three options: agree fully (A+), agree partially (A-), or disagree (D). In Sub-Section 3 (see Table 3), respondents were required to respond to 22 items related to the causes of TBP with three options: major $(\mathrm{M}+)$, minor $(\mathrm{M}-)$, or none $(\mathrm{N})$. 
Cronbach's alpha coefficient values were used to determine the reliability (internal consistency) of the scores. The observed Cronbach's coefficients alpha values of 0.87 and 0.88 , respectively, for the scores measuring the the incidence and causes of TBP, were much higher than 0.70 - the minimum value regarded as significant, thus confirming the scores' reliability.

\section{DATA ANALYSIS}

Descriptive statistics are used to summarise the sample statistics. The characteristics of the participants are summarised in Table 1 to reflect the representativeness of the sample.

\section{Biographical Data of Participants}

Table 1: Participants' Characteristics $(n=311)$

\begin{tabular}{|c|c|c|c|c|c|}
\hline Site & $\mathbf{n}$ & $\%$ & Grades and Phases & $\mathbf{n}$ & $\%$ \\
\hline Port Elizabeth & 245 & 78.8 & $1-3$ & 13 & 4.2 \\
\hline Durban & 66 & 21.2 & $4-6$ & 31 & 9.9 \\
\hline \multicolumn{3}{|l|}{ Post Level } & $7-9$ & 113 & 36.3 \\
\hline Teacher & 216 & 69.5 & $10-12$ & 151 & 48.6 \\
\hline Head of Department & 45 & 14.5 & Other & 3 & 1.0 \\
\hline Deputy Principal & 34 & 10.9 & \multicolumn{3}{|l|}{ Highest Qualification } \\
\hline Principal & 10 & 3.2 & Grade 12 or lower & 0 & 0.0 \\
\hline Other & 6 & 1.9 & Teaching Diploma & 51 & 16.4 \\
\hline \multicolumn{3}{|l|}{ Home Language } & Degree & 88 & 28.3 \\
\hline English & 142 & 45.7 & Degree + Teaching Diploma & 102 & 32.8 \\
\hline Afrikaans & 56 & 18.0 & $\begin{array}{l}\text { Postgraduate Degree } \\
\text { Postgraduate Degree }+ \text { Teaching Diploma }\end{array}$ & $\begin{array}{l}17 \\
53\end{array}$ & $\begin{array}{c}5.5 \\
17.0\end{array}$ \\
\hline Xhosa & 93 & 29.9 & \multicolumn{3}{|l|}{ Years' Teaching Experience } \\
\hline Zulu & 19 & 6.1 & $0-2$ & 26 & 8.4 \\
\hline \multirow[t]{2}{*}{ Other } & 1 & 0.3 & $3-4$ & 15 & 4.8 \\
\hline & & & $5-9$ & 31 & 10.0 \\
\hline \multicolumn{3}{|l|}{ Age } & $10-19$ & 119 & 38.3 \\
\hline $20-29$ & 42 & 13.5 & $20+$ & 120 & 38.5 \\
\hline $30-39$ & 56 & 18.0 & \multicolumn{3}{|l|}{ School Type } \\
\hline $40-49$ & 139 & 44.7 & Ex-Model C School & 61 & 19.6 \\
\hline $50-59$ & 69 & 22.2 & Section 21 Urban State School & 141 & 45.3 \\
\hline $60+$ & 5 & 1.6 & Section 21 Rural State School & 15 & 4.8 \\
\hline \multicolumn{3}{|l|}{ Gender } & Independent School & 38 & 12.2 \\
\hline Male & 111 & 35.7 & Non-section 21 Urban State School & 38 & 12.2 \\
\hline \multirow[t]{2}{*}{ Female } & 200 & 64.3 & Non-section 21 Rural State School & 10 & 3.2 \\
\hline & & & Farm School & 8 & 2.7 \\
\hline
\end{tabular}

\section{Current Incidence of TBP}

Statistics summarising the responses to the items relating to the incidence of TBP are reported in Table 2. The mean and standard deviation (SD) are also indicated. A total of $96.8 \%$ of the participants agreed that the incidence of TBP is not restricted to any racial or cultural group. Only $6.8 \%$ of the participants disagreed that educators in under-resourced schools suffer greater from TBP when compared to educators in well-resourced schools. Almost all the participants (99.7\%) agreed that the degree of the effects of TBP depended on the circumstances that prevailed in the educational milieu. Only $6.1 \%$ of the participants disagreed that most educators suffer from TBP. Regarding the professional competencies of teachers, $88.8 \%$ agreed that educators lacking the knowledge and skills to teach their subjects would suffer to a greater extent from TBP than those teachers who were professionally competent. Teachers cannot have confidence in curriculum practices they don't have a clue on how to implement in their classrooms. Simply urging teachers to have high expectations for themselves without enhancing their expertise, is not only inadequate, but can be counterproductive and to the detriment of their pupils (Hawley \& Nieto, 2010). Parental involvement in education is important to reduce the risk of failure of pupils and only $20 \%$ of the participants disagreed with this issue. 
Table 2: Current incidence of TBP $(n=311)$

\begin{tabular}{|c|c|c|c|c|c|}
\hline & Agree fully \% & Agree partially \% & Disagree \% & Mean & SD \\
\hline $\begin{array}{l}\text { The incidence of TBP is not restricted to any } \\
\text { racial or cultural group. }\end{array}$ & 76.5 & 20.3 & 3.2 & 1.27 & 0.51 \\
\hline $\begin{array}{l}\text { Educators in under-resourced schools suffer to } \\
\text { a greater extent from TBP than educators in } \\
\text { well - resourced schools. }\end{array}$ & 76.2 & 17 & 6.8 & 1.29 & 0.46 \\
\hline $\begin{array}{l}\text { The degree of the effects of TBP on teachers } \\
\text { varies from slight to significant, depending on } \\
\text { teachers' circumstances within a specific } \\
\text { teaching environment. }\end{array}$ & 71.1 & 28.6 & 0.3 & 1.31 & 0.59 \\
\hline Most educators suffer from TBP. & 68.8 & 25.1 & 6.1 & 1.37 & 0.6 \\
\hline $\begin{array}{l}\text { TBP is experienced to a greater extent by } \\
\text { educators who lack the knowledge to provide } \\
\text { learners with quality and equal education. }\end{array}$ & 65.3 & 23.5 & 11.2 & 1.46 & 0.69 \\
\hline $\begin{array}{l}\text { There is a higher incidence of TBP where } \\
\text { learners' parents are in full-time employment. }\end{array}$ & 43.7 & 36.3 & 20 & 1.76 & 0.76 \\
\hline
\end{tabular}

From Table 2, it is clear that the majority of the participants agreed fully or partially to the incidence of TBP in schools where they are teaching.

\section{Causes of TBP}

Statistics summarising the responses to the items relating to the causes of TBP are reported in Table 3 . The mean and SD are also indicated.

Table 3: Causes of TBP $(n=311)$

\begin{tabular}{|c|c|c|c|c|c|}
\hline & Maior \% & Minor \% & None \% & Mean & SD \\
\hline Teachers burdened with administrative work & 91.0 & 8.4 & 0.6 & 1.1 & 0.32 \\
\hline $\begin{array}{l}\text { Language of teaching and learning is not the same as the } \\
\text { mother tongue of learners }\end{array}$ & 84.6 & 14.1 & 1.3 & 1.17 & 0.41 \\
\hline $\begin{array}{l}\text { Unrealistic expectation of paradigm shifts from teachers to } \\
\text { cope with changes in education }\end{array}$ & 83.9 & 15.1 & 1.0 & 1.17 & 0.40 \\
\hline Lack of disciplinary measures in schools & 82.3 & 13.2 & 4.5 & 1.2 & 0.46 \\
\hline $\begin{array}{l}\text { Transformation in education without supporting } \\
\text { infrastructures }\end{array}$ & 82.0 & 15.8 & 2.2 & 1.21 & 0.45 \\
\hline $\begin{array}{l}\text { Lack of provision in the mainstream curriculum for learners } \\
\text { with special needs }\end{array}$ & 81.7 & 13.8 & 4.5 & 1.21 & 0.47 \\
\hline Lack of professional support from district officials & 81.4 & 16.1 & 2.5 & 1.22 & 0.51 \\
\hline Lack of parental involvement in education & 80.7 & 17.4 & 1.9 & 1.23 & 0.52 \\
\hline Violent behaviour of learners & 75.2 & 19.3 & 5.5 & 1.28 & 0.52 \\
\hline $\begin{array}{l}\text { Lack of provision in the mainstream curriculum for gifted } \\
\text { learners }\end{array}$ & 75.2 & 21.2 & 3.6 & 1.3 & 0.57 \\
\hline Drug abuse amongst learners & 70.7 & 21.6 & 7.7 & 1.37 & 0.62 \\
\hline $\begin{array}{l}\text { Limited opportunities for teachers to upgrade their } \\
\text { professional knowledge and skills }\end{array}$ & 66.6 & 25.1 & 8.3 & 1.39 & 0.57 \\
\hline Poverty & 65.3 & 30.2 & 4.5 & 1.42 & 0.64 \\
\hline Teaching the same curriculum to all learners & 64.3 & 27.7 & 8.0 & 1.44 & 0.64 \\
\hline Poor assessment techniques & 60.5 & 34.7 & 4.8 & 1.44 & 0.59 \\
\hline Crime within the community & 58.8 & 29.6 & 11.6 & 1.51 & 0.65 \\
\hline Poor relations between principal and staff & 57.9 & 31.5 & 10.6 & 1.53 & 0.67 \\
\hline Inequality in education & 57.6 & 34.1 & 8.3 & 1.53 & 0.68 \\
\hline Using the same curriculum for group work & 57.2 & 32.8 & 10.0 & 1.53 & 0.69 \\
\hline HIV/AIDS affecting learners & 53.1 & 34.7 & 12.2 & 1.59 & 0.7 \\
\hline HIV/AIDS affecting teachers & 48.6 & 37.0 & 14.4 & 1.66 & 0.72 \\
\hline Racism in education & 40.5 & 42.8 & 16.7 & 1.76 & 0.72 \\
\hline
\end{tabular}


The largest proportion of the sample (91\%) perceived administrative work as the major cause of TBP for teachers. The second major cause of TBP (84.6\%) is when the language of teaching and learning is not the same as the mother tongue of the learners. Cognitive dissonance will be experienced by learners when they do not comprehend the subject matter taught to them in a language that they do not use as a medium of communication (Singh, 2010; Singh, 2011). Several additional issues pertaining to the curriculum were identified as causes of TBP:

- $\quad$ Providing for gifted pupils (96.4\%)

- $\quad$ Special needs of learners $(95.5 \%)$

- $\quad$ Lack of effective assessment instruments (95.2\%)

- $\quad$ Teaching the same curriculum to all learners $(92 \%)$

- $\quad$ Inequality in education $(91.7 \%)$

- Using the same curriculum for group work (90\%)

- $\quad$ Racism in education (83.3\%).

Research shows that learners taught by incompetent teachers experience cognitive dissonance resulting in lasting decreased achievement (Dawson \& Billingsley, 2000; Sanders \& Horn, 1998; Jones, 1997; Tucker, 1997; Neill \& Custis, 1978). There is ample evidence that poor teaching materially contributes to higher levels of failure rates amongst learners (Fuhr, 1993, p. 26). Searle (2013) affirms that in order to tackle tough learning issues, educators must examine and update their traditional instructional practices. She suggests that three big changes are often needed to avoid the common pitfalls in addressing curriculum problems such as using the same curriculum to cater for different ability needs:

1. Focus on what blocks pupil learning before concentrating on which intervention to use

2. Minimize the guessing factor by staying informed on current brain and educational research

3. Train for and monitor the implementation of interventions. The development of teachers' professional competencies is necessary to know how instructional interventions must be planned, implemented, and assessed to be assured of a significant change in pupil achievement levels. (p. 3)

Compelling evidence further affirms that when teachers create high expectations for their learners who have been marginalized by their schooling experiences, student learning will be enhanced as long as high expectations are linked to greater resources and support (Hawley \& Nieto, 2010). Hawley and Nieto (2010) believe that we need to "recognize an inconvenient truth - that when it comes to maximizing learning opportunities and outcomes for students from racially and ethnically diverse backgrounds, race, and ethnicity matter" (p. 66). They assert that race and ethnicity influence teaching and learning in two important ways:

- $\quad$ They affect how learners respond to instruction and curriculum.

- $\quad$ They influence teachers' assumptions about how pupils are capable of learning.

However, Hawley and Nieto (2010) express a word of caution by pointing out that the differences among people to whom we assign racial and ethnic identities have no biological basis and are the product of socially constructed beliefs that can and must be changed through social action. They insinuate that:

Although color-blindness is a good thing when it means that people do not discriminate on the basis of race, it can have negative consequences when educators refuse to see their students' racial, ethnic, cultural, and linguistic differences. Instead, teachers need to respect and build on differences to foster student learning. (p. 67-68).

The following items evoke the causes of TBP associated with the lack of support provided to teachers:

- $\quad$ Coping with changes in education (99\%)

- $\quad$ Educational transformation without supporting infrastructures $(97.8 \%)$

- $\quad$ Lack of support from district officials $(97.5 \%)$

- $\quad$ Upgrading teachers knowledge and skills (91.7\%)

- $\quad$ Poor relationships between the principal and teachers $(89.4 \%)$ 
Lack of discipline, violence in schools, drug abuse, and crime are additional causes of TBP in the school environment as confirmed by the participants' responses:

- $\quad$ Lack of disciplinary measures $(95.5 \%)$

- $\quad$ Pupils' violent behaviour (94.5\%)

- $\quad$ Drug abuse by pupils in schools (92.3\%)

- $\quad$ Crime within the community $(88.4 \%)$

Teachers in high-poverty schools are more likely to report problems of pupil misbehaviour, absenteeism, and lack of parental involvement than teachers in low-poverty schools and are more likely to drop out of high school (Gandara, 2010). A total of $65.3 \%$ of the participants indicated that poverty was a major cause of TBP in schools. However, a total of $80.7 \%$ of the participants believe that the lack of parental involvement in education is one of the causes of TBP. Only $48.6 \%$ of the participants indicated that HIV/AIDS affecting teachers was a major cause of TBP. In contrast, $53.1 \%$ of the participants indicated that HIV/AIDS affecting learners was a major cause of TBP. Doing one's best and not achieving the objectives of the organization is unsatisfactory, as affirmed by Filochowski (2013):

People do what they can and if it doesn't work, they think they have done their best. They don't work to agreed goals and targets, so there isn't regular feedback within the organisation that things are going wrong and that something needs to be done. (p. 63)

The fear of failure in education can lead teachers to have a low self-esteem and lack of motivation, lose their passion to teach, become indifferent to innovations in education, and leave the profession (McKay, 2000; Martin \& Marsh, 2003; Singh, 2011; Singh, 2013a). When widely publicized questions emerge about a failing educational system, then uncertainty and fear are inevitable outcomes (Ginsberg \& Lyche, 2008; Grant, 2009). Studies (Martin \& Marsh, 2003; Gardner \& Bell, 2005; Singh, 2011; Lunn, 2009; Wildemann, 2009; Singh \& Morar, 2009) indicate that TBP can drain teachers of their motivation and inspiration and it prevents them from realising their full potential as it impacts negatively on them personally, their teaching, on learners and on the teaching profession.

\section{RECOMMENDATIONS}

Rather than fearing mistakes, individuals need to welcome them during the learning process because employees who are afraid to make mistakes would experience problems in overcoming the hurdles of change in their organizations (McKay, 2000). As affirmed by McKay (2000), mistakes are information about what works and what doesn't - they have nothing to do with one's worth or intelligence because they are merely steps to a goal. Emotional intelligence, if properly nurtured, should provide employees with the inner resilience that is necessary for negotiating their way through feelings of distress, low self-evaluation, internal defeatism, general depression, and associated with TBP (Holden, 2005). As outlined below, the situation in schools can be improved by addressing the real concerns of the teachers regarding curriculum changes, class sizes, safety issues, dealing with multiculturalism and multilingualism, and catering for the individual needs of learners with diverse abilities in heterogeneous classrooms.

1. TBP needs to be recognised fully by the Department of Education (DoE) and educators need to be provided with adequate measures to combat its effects.

2. The causes of TBP need to be addressed by the DoE on national, provincial, and local levels.

3. The concept of multilingual teaching is a great and idealistic one; however, very little has been put into place by the DoE to support both the teachers and learners to achieve true success in such an environment. Schools must be provided with trained translators who are flexible and able to assist teachers and learners in each phase of learning. These translators must be able to function successfully on the level of both the teacher and learner. Hence, there must be a language policy in schools which accommodate those learners who have learning barriers specifically related to that of language.

4. A qualified psychologist, therapist, social worker, and remedial teacher must be appointed in all schools.

5. Schools need to be well-resourced to support constant curriculum changes. 
6. Specialist teachers need to be appointed to cater for the special needs of learners. Also, new subjects are constantly introduced into the curriculum and therefore teachers specifically trained in these subjects must be appointed in schools.

7. School violence must be prevented and adequate security measures must be put into place by the DoE. Furthermore, the carrying of weapons by learners in their schools must be banned. Sale of drugs off and on the school premises to learners must be appropriately addressed by the school management.

8. The number of pupils in a class should be limited to a maximum of twenty-five. This would allow for individualization and differentiation to take place effectively.

9. Placement of learners with special needs in the mainstream of education must be reconsidered by the DoE. Teachers with specialized training need to teach these learners. Preferably, special classes should be created in schools to address their specific learning needs.

10. Professional training programmes for teachers, especially in higher education institutions, must include fear management. Qualifications in teacher training must include managing fear in education as an essential part of the programme. The work integrated learning experiences of educators must include extensive training on how to cope with TBP.

As pointed out by Eisner (1995), the reform of education not only requires a deeper and more comprehensive analysis of schools, but it must also attend to the dimensions of schooling that need to be collectively addressed to make educational reform educationally real. In managing TBP, all stakeholders in education need to find a solution to many pressing problems being experienced in education. Issues such as curriculum change without the professional development of teachers cannot be ignored. TBP is evident in unsafe environments. Counsellors and psychologists should be reinstated in schools to support the teachers in addressing matters such as drug abuse. Security needs to be beefed up in schools so that learning environments are happy places for both teachers and their learners. TBP is not a myth, but a harsh reality affecting teaching and learning outcomes in schools. Fear to address its existence can only exacerbate the challenges facing all stakeholders in this millennium to provide quality and equal education for all learners.

\section{CONCLUSION}

In this exploratory study, educators, as the employees in their respective organizations, gave a clear indication of their perceptions of the current incidence and causes of TBP as it affects them in their working environment. The findings indicate that the job performance of employees can be severely restricted when they experience job training deficits. This will inevitably expose the employees to the effects of TBP, which is not necessarily restricted to any organization, whether it falls within the domain of the public or private sector. As the findings of this exploratory study strongly suggest, employers must not be complacent and evasive by ignoring problems that fester within their organizations. Without the supporting infrastructure and expecting employees to do the work that they are not trained to do, it can be detrimental in terms of organizational outputs. This study has further revealed that when an organization, like a school, is obsessed with a single goal at the expense of others, it can plunge into trouble when things fail to work out. A culture of false assurance is typical of tobephobic leadership in organizations that fail to deliver promised outputs. More research needs to be done on employees' perceptions of their experiences of TBP in other organizations within the public and private sectors.

\section{AUTHOR INFORMATION}

Prakash Singh is a professor at the Nelson Mandela Metropolitan University in Port Elizabeth, South Africa. He is an NRF rated researcher and a Fulbright scholar. His niche research areas of publication are organizational behaviour and social psychology. Professor Singh is the author of Innovative Strategies to Develop Better Schools and co-author of Principal Leadership. He has also published widely in peer-reviewed journals and has presented numerous papers at international conferences. E-mail: Prakash.Singh@nmmu.ac.za

\section{REFERENCES}

1. Atkinson, J. W. (1957). Motivational determinants of risk taking behaviour. Psychological Review, 64, 359-372. 
2. Atkinson, J. W. (1964). An introduction to motivation. Princeton, NJ: Van Nostrand.

3. Benoit, G., Lecocq, C., \& Phillippot, P. (2007). School violence and teacher professional disengagement. British Journal of Educational Psychology, 77(2), 465-477.

4. Birney, R. C., Burdick, H., \& Teevan, R. C. (1969). Fear offailure. New York: Van Nostrand.

5. Carter, G. R. (2007). South Africa focuses on leadership standards for principals. Education Update, 49(4), 1-8.

6. Cassidy, S. (2006). Staff tell of 'climate of fear' in schools. The Independent. London, April 15, 2006.

7. Chong, L. (2005). Do anxious and fearful teachers learn in classroom situations? Retrieved from http://www.cdtl.nus.edu.sg/link/Jul2005/pd.htm

8. Clarkson, M. (2004). Quick fixes for everyday fears. Toronto: Key Porter Books Limited.

9. Conley, S., \& Glasman, N. S. (2008). Fear, the school organization, and teacher evaluation. Educational Policy, 22(1), 63-85.

10. Dawnward, D. (2010). Tobephobia. Port Elizabeth: Nelson Mandela Metropolitan University.

11. Dawson, T. C., \& Billingsley, K. L. (2000). Unsatisfactory performance: How California's K-12 education system protects mediocrity and how teacher quality can be improved. San Francisco: Pacific Research Institute for Public Policy.

12. Eisner, E. W. (1995). Educational reform and the ecology of schooling. In A. C. Ornstein \& L. S. Behar (eds.), Contemporary issues in curriculum. Boston: Allyn \& Bacon.

13. Elliot, A. J., \& Thrash, T. M. (2004). The intergenerational transmission of fear of failure. Personality and Social Psychology Bulletin, 30, 957-971.

14. Engelbrecht, P., Oswald, M., Swart, E., \& Eloff, I. (2003). Including learners with intellectual disabilities: Stressful for teachers? International Journal of Disability, Development and Education, 50(3), 293-308.

15. Filochowski, J. (2013). Too good to fail. New York: Pearson.

16. Fuhr, D. L. (1993). Managing mediocrity in the classroom: School leaders must rescue students from borderline teachers. The School Administrator, 50(4), 26-29.

17. Gandara, P. (2010). Overcoming triple segregation. Educational Leadership, 68(3), 60-64.

18. Gardner, J., \& Bell, A. H. (2005). Phobias and how to overcome them: Understanding and beating your fears. New Jersey: New Page Books.

19. Gastorf, J. W., \& Teevan, R. C. (1980). Type A coronary-prone behaviour pattern and fear of failure. Motivation and Emotion, 4(1), 71-76.

20. Ginsberg, R., \& Cooper, B. S. (2008). Introduction. What's fear got to do with it? Educational Policy, 22(1), 5-9.

21. Ginsberg, R., \& Lyche, L. F. (2008). The culture of fear and the politics of education. Educational Policy, 2(1), 10-27.

22. Giroux, H. A. (2003). The abandoned generation: Democracy beyond the culture of fear. London: McMillan.

23. Grant, N. (2009). Schools of little thought: Why change management hasn't worked. Improving Schools, 12(1), 19-32.

24. Gravetter, F. J., \& Wallnau, L. B. (2008). Essentials of statistics for the behavioural sciences. Belmont, CA: Thomson.

25. Greenberg, J., \& Baron, R. A. (2000). Behavior in organizations. New Jersey: Prentice Hall.

26. Harford, T. (2011). Adapt: Why success always starts with failure. London: Abacus.

27. Hawley, W. D., \& Nieto, S. (2010). Another inconvenient truth: Race and ethnicity matter. Educational Leadership, 68(3), 66-71.

28. Holden, R. (2005). Success intelligence. London: Hodder \& Stoughton.

29. Jali, B. P. (2010). What are the effects of Tobephobia on teaching and learning? Port Elizabeth: Nelson Mandela Metropolitan University.

30. Jones, R. (1997). Showing bad teachers the door. American School Board Journal, 184(11), $20-24$.

31. Kyriacou, C. (1998). Teacher stress: Past and present. In J. Dunham \& V. Varma (eds.), Stress in teachers. London: Whurr.

32. Leach, J. (2013). The success factor. Petaling Jaya, Malaysia: Advantage Quest Publications.

33. Lunn, C. (2009). Tobephobia. Port Elizabeth: Nelson Mandela Metropolitan University.

34. Martin, A. J., \& Marsh, H. W. (2003). Fear of failure: Friend or foe? Australian Psychologist, 38(1), 31-38.

35. Maxwell, J. C. (2001). Think on these things: Meditations for leaders. New York: Christian Art Publishers. 
36. McClelland, D. C., Atkinson, J. W., Clark, R. W., \& Lowell, E. L. (1953). The achievement motive. New York: Appleton.

37. McGregor, H. A., \& Elliot, A. J. (2005). The shame of failure: Examining the link of fear of failure and shame. Personality and Social Psychology Bulletin, 31, 218-231.

38. McKay, M. (2000). Self-esteem. Oakland, CA: Harbinger.

39. McMillan, J. H., \& Schumacher, S. (2001). Research in education: A conceptual introduction. New York: Harper.

40. Menuey, B. P. (2005). Teachers' perceptions of professional incompetence and barriers to the dismissal process. Journal of Personnel Evaluation in Education, 18, 309-325.

41. Neill, S. B., \& Custis, J. (1978). Staff dismissal: Problems and solutions. Arlington, VA: American Association of School Administrators.

42. Ornstein, A. C., \& Hunkins, F. P. (2004). Curriculum: foundations, principles and issues. New York: Pearson.

43. Rooney, J. (2010). Crisis as opportunity. Educational Leadership, 68(3), 87-88.

44. Rothstein-Fisch, C., \& Trumball, E. (2008). Managing diverse classrooms. Alexandria, Virginia: Association for Supervision and Curriculum Development.

45. Sanders, W. L., \& Horn, S. P. (1998). Research findings from the Tennessee value-added assessment system. Journal of Personnel Evaluation in Education, 12, 247-256.

46. Scherer, M. (2010). Getting a grip on the gaps. Educational Leadership, 68(3), 7.

47. Searle, M. (2013). Causes and cures in the classroom. Alexandria, VA: Association for Supervision and Curriculum Development.

48. Singh, P., Manser, P., \& Dali, C. (2013). Principal leadership. Saarbrucken, Germany: Lap Lambert Academic Publishing.

49. Singh, P., \& Morar, T. (2009). Tobephobia: fear of failure experienced by educators. The International Journal of Knowledge, Culture and Change Management, 9(4), 93-105.

50. $\quad$ Singh, P. (2006). Are you suffering from TBP? The Teacher, November 2006.

51. Singh, P. (2008). The effects of Tobephobia on learning outcomes in the educational milieu. International Journal of Learning, 15(4), 110-120.

52. Singh, P. (2010). Innovative strategies to develop better schools. Sydney, Australia: Common Ground.

53. Singh, P (2011). Tobephobia experienced by teachers in secondary schools: An exploratory study focusing on curriculum reform in the Nelson Mandela Metropole. Africa Education Review, 8(2), 372-388.

54. Singh, P. (2013a). Fear abounds in the educational environment: Teachers' professional competencies in the management of knowledge. International Business and Economics Research Journal, 12(6), 687-700.

55. Singh, P. (2013b). A collegial approach in understanding leadership as a social skill. International Business and Economics Research Journal, 12(5), 489-502.

56. South African Human Rights Commission (SAHRC) (2006). Report of the public hearing on school-based violence. Pretoria. Retrieved from http://www.sahrc.org.za/sahrc_cms/publish/cat_index_41.shtml

57. Tucker, P. D. (1997). Lake Wobegon: Where all teachers are competent. Journal of Personnel Evaluation in Education, 11,103-126.

58. Tuckman, B. W. (1999). Conducting educational research. New York: Harcourt Brace.

59. Wildemann, V. A. R. (2009). The potential impact of Tobephobia on South African educators. Port Elizabeth: Nelson Mandela Metropolitan University.

60. Wright, A. G. C., Pincus, A. L., Conroy, D. E., \& Elliot, A. J. (2009). The pathoplastic relationship between interpersonal problems and fear of failure. Journal of Personality, 77(4), 997-1024. 